Voix et Images

voixetimages

\title{
Le passeur désenchanté
}

\section{François Paré}

Volume 32, numéro 1 (94), automne 2006

Denis Vanier

URI : https://id.erudit.org/iderudit/014709ar

DOI : https://doi.org/10.7202/014709ar

Aller au sommaire du numéro

\section{Éditeur(s)}

Université du Québec à Montréal

\section{ISSN}

0318-9201 (imprimé)

1705-933X (numérique)

Découvrir la revue

\section{Citer cet article}

Paré, F. (2006). Le passeur désenchanté. Voix et Images, 32(1), 135-140.

https://doi.org/10.7202/014709ar d'utilisation que vous pouvez consulter en ligne.

https://apropos.erudit.org/fr/usagers/politique-dutilisation/ 


\author{
E S S A I S / ÉT U D E S \\ Le passeur désenchanté \\ $++$
}

FRANÇOIS PARÉ

Université de Waterloo

Le sujet me semblait usé jusqu'à la corde. Je me suis dit avant de commencer à rédiger cette chronique: «Voilà, c'est mon dernier texte sur l'altérité et la migrance ! C'est fini. Je ne retournerai plus dans ces paysages littéraires coupés à blanc. Les études sur la question continueront sans doute à atterrir sur mon pupitre au même rythme où, depuis une quinzaine d'années, elles arrivent au secrétariat de Voix et Images. Ces recherches ne s'arrêteront pas sur la foi de mon désenchantement, c'est évident. Mais il faudra éventuellement que je dise non.»

Il est vrai que le Québec a produit une large part d'études, certaines d'une grande nouveauté, sur la question de l'altérité et de la conscience migrante. Dans ce vaste chantier, comme le notait récemment Antonio D'Alfonso, il s'agissait d'opérer une mutation du discours identitaire, afin d'offrir à la modernité québécoise une voie moins conflictuelle, "qui permettrait de considérer deux éléments opposés, non comme des forces contraires, mais comme une source d'énergie qui nous donnerait de quoi sortir d'un cercle vicieux et qui nous empêcherait de retourner à notre point de départ ${ }^{1}$ ». Peu à peu, à force d'arpenter les mêmes terres, cependant, cette énergie intellectuelle s'est dissipée, ne laissant que des ambiances préfabriquées dont persiste à se nourrir le discours critique sur la littérature. Certaines interventions récentes annoncent peut-être un changement de paradigme.

Dans Les dépouilles de l'altéritéé, son dernier livre, Daniel Castillo Durante s'efforce de distinguer l'univers figé du stéréotype, auquel les figures d'altérité sont presque toujours réduites, et le vide mélancolique que les formes figées de l'autre recèlent toujours. Dans cette perspective, l'altérité n'apparaît que dans la «pétrification du langage». Les catégories de l'étranger et du migrant ne donnent

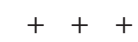

1 Antonio D'Alfonso, En italiques, Ottawa, Éditions L'Interligne, 2005, p. 59. 2 Daniel Castillo Durante, Les dépouilles de l'altérité, Montréal, XYZ éditeur, coll. «Théorie et littérature», 2004, 201 p. 
plus cours à des interprétations libératrices et ludiques. Pour Castillo Durante, la notion d'altérité se dérobe à elle-même, emportée par une vacuité qu'elle ne peut plus dissimuler. Ainsi, l'exilé devient profondément mélancolique devant le sentiment de la perte qui le hante et il ne trouve à s'exprimer que dans les paramètres d'un deuil difficilement assumé de l'origine: «Parler toujours, jusqu'à l'infini de l'objet perdu. En dernière instance, la perte est à la base de la mélancolie de l'étranger. L'écrivain en tant qu'étranger n'écrit que pour s'appartenir. Voilà son espoir et son leurre en même temps.» (200) Par son pessimisme, le livre de Castillo Durante marque un tournant théorique important, puisqu'il cherche à rendre compte de l'épuisement des concepts clés d'altérité et de migrance dans le discours intellectuel en Occident.

Selon Castillo Durante, la notion d'altérité ne saurait être pensée aujourd'hui en dehors de l'érosion spectaculaire des figures de l'identité dans le contexte de la mondialisation des marchés économiques. En effet, l'autre constitue, dans sa singularité, un gênant obstacle à la libre circulation des ressources matérielles et humaines. Si l'altérité a pu se profiler comme une instance positive dans les théories récentes de la migrance, c'est qu'elle était le produit d'un humanisme bienveillant qui ne donnait pas à voir «la dégradation, l'avilissement et l'humiliation de l'autre » (63) dans les sociétés contemporaines. Désormais, soutient Castillo Durante, les figures de l'altérité sont dépourvues de légitimité dans une culture du vide qui cherche à aplanir tout jaillissement de la différence: "C'est comme si les cultures sous le mode de la reproduction technique des images se devaient d'exonérer leur responsabilité devant la mort de l'original par une exacerbation de l'identification au même.» (64) L'autre n'est alors plus qu'une "dépouille», puisque son identité propre se laisse saisir par une profonde et paradoxale expérience de la perte.

L'ouvrage de Daniel Castillo Durante confirme, en fin de compte, le déplacement du concept de migrance vers celui d'exil. Bien qu'elle soit hautement ritualisée et surtout valorisée dans les sociétés multiculturelles contemporaines, l'émigration reste un traumatisme fondamental, associé à une expérience de la mort. Ayant vécu une douloureuse rupture avec un temps et un lieu donnés, l'exilé paie chèrement sa lucidité particulière, puisqu'il cherche sans cesse dans l'expérience de son déplacement - dans l'ici et le là-bas de la migration - la «dépouille» de son identité. Castillo Durante note qu'on peut bien «rêver la destruction des limites territoriales ", il est aussi essentiel de s'interroger sur la "notion détestable de lieu» si l'on veut comprendre les dispositifs d'assujettissement mis en place par les pouvoirs (115). Au-delà de certains aspects excessifs, son analyse appelle à repenser les «figures les plus intenses de l'altérité: le déraciné, l'exilé, le diasporique, le nomade, l'itinérant» (165). Il en résulte un livre où se superposent une pressante incitation au changement et une profonde mélancolie devant la fixité des formes identitaires qui nous sont offertes.

Les propos de Daniel Castillo Durante dans Les dépouilles de l'altérité convoquent les réflexions plus récentes de Simon Harel sur la notion de «communautés culturelles» 
en littérature québécoise. Dans Les passages obligés de l'écriture migrante ${ }^{3}$, Simon Harel s'en prend au concept de pluralisme culturel derrière lequel se cachent, selon lui, une appropriation "désarmante » et une «banalisation » prescriptive de l'altérité, concept qui ne sert plus alors que de monnaie d'échange dans un cadre économique dévalorisant. Au Québec, les «discours euphoriques sur la migration» ont donné lieu à une pléthore de réflexions conventionnelles, comme si le déplacement identitaire ou l'exil migratoire était « devenu la forme postindustrielle de la délocalisation marchande» (51). Tout en mettant en cause le nationalisme identitaire, de nombreux intellectuels québécois ont fait leur l'apologie sans réserve de l'individualisme, comme si les attaches collectives avaient tout à coup perdu toute validité devant le rêve d'une société égalitaire et plurielle. Harel reconnaît aujourd'hui que cette perspective était réductrice, parce qu'elle ne tenait pas compte des enjeux collectifs de l'identité, même dans les sociétés postmodernes. À la manière d'Augustin Berque et de Peter Sloterdijk, il nous invite à chercher de nouveaux modes d'habitabilité qui ne fassent plus abstraction des solidarités territoriales et des réseaux communautaires.

Pour Harel, la notion de migrance est tronquée, dans la mesure où elle se limite à une conception temporelle de la revendication identitaire. Pour arriver à tracer la ligne qui le séparera définitivement de son passé et à inscrire le présent dans une pluralité nouvelle, l'écrivain migrant transpose trop souvent son récit identitaire sur le strict plan de la mémoire, occultant ainsi le lieu où se jouent les hybridités et les appartenances: "Cette relation au temps se substitue en fait à une compréhension topographique de la migration. » (57) Afin de rétablir la complexité de la notion de migrance, Harel propose dès lors de revenir à certaines œuvres dans lesquelles s'exprimait, dès les années 1990, le «témoignage » d'une étrangeté irréductible de la posture du migrant.

Dans un chapitre intitulé «Origines et pérennité de la transculture», Harel retrouve dans les écrits de Marco Micone, d'Antonio D'Alfonso, de Fulvio Caccia et de Lamberto Tassinari une problématisation du rapport collectif que les théories subséquentes de la migrance ont plutôt passée sous silence. L'admiration du critique pour ces quatre écrivains est sans réserve: "Ces intellectuels et écrivains italoquébécois auront sans doute été parmi les premiers à faire le deuil de leur ethnicité afin de promouvoir un nouveau mode de représentation du collectif au Québec.» (75) S'ils refusent la pensée ethniciste, Micone, D'Alfonso et Caccia s'interrogent du même souffle sur le bien-fondé d'une société qui serait sans "cartographie affective» (77). Ce qui fascine chez ces auteurs, selon Harel, c'est donc la recherche d'une voie mitoyenne qui, tout en étant ouverte à la pluralité, ne renoncerait pas pour autant à inscrire le «transculturel» dans des paysages reconnaissables et enracinés.

Le chapitre que consacre l'auteur à l'analyse de La Québécoite de Régine Robin me semble singulièrement important. En effet, le roman de Robin est central

$$
++
$$

3 Simon Harel, Les passages obligés de l'écriture migrante, Montréal, XYZ éditeur, coll. "Théorie et littérature ", 2005, 250 p. 
à la notion de migrance identitaire. Harel y voit la recherche d'une «écriture du horslieu ", Montréal n'étant pas le territoire cosmopolite dont on a souvent souligné la présence dans cette œuvre, mais plutôt un espace de déréliction, marquée par une profonde «illisibilité». Certes, l'héroïne de La Québécoite se souvient avec tendresse des lieux quittés, mais elle comprend que «la mémoire est tout au plus quelque chose de dérisoire et que le sursaut nostalgique ne permet pas de prêter forme à l'expérience migratoire» (156). Le roman de Régine Robin indiquerait ainsi le refus de la filiation et la quête du renouvellement dans une «ville désémantisée» (162).

Cette analyse remarquable - comme celles que Harel consacre également à Émile Ollivier et à Antonio D'Alfonso - correspond à une profonde transformation du paradigme de la migrance. En effet, pour Harel, il ne nous est plus possible de faire comme si l'espace migratoire était déshabité. Cette illusion ne ferait que reconduire le discours économique dominant de la délocalisation: "Nous avons épuisé en ce début de Xxi siècle, les charmes de la virtualité: le réel s'annonce dans sa brutale consistance. Comme si nous comprenions enfin notre obligation de solidarité avec le monde à venir...» (208) Par sa sensibilité singulière devant la complexité de l'expérience migratoire et par son indéniable courage intellectuel, le livre de Simon Harel transforme intimement notre compréhension souvent béate des phénomènes de la migrance et du déplacement identitaires. Il s'oppose avec force à tous les "ghettos intellectuels» qui finissent par nous servir de caution et il en appelle au «génie du lieu » qui nous guidera éventuellement vers d'autres habitabilités moins inquiètes.

Je voudrais maintenant me consacrer à deux ouvrages européens sur les mêmes questions. Un premier livre, Altérité et insularité ${ }^{4}$, dirigé par Alessandra Ferraro et issu du colloque éponyme de mai 2002 à Udine en Italie, s'inscrit pleinement dans le sillage des études récentes sur les espaces insulaires. Dans ce recueil, trois études seulement portent sur la littérature québécoise. L'article d'Alessandra Ferraro sur l'altérité du corps chez Marie de l'Incarnation offre une relecture de quelque trois cents lettres, formant le volume de correspondance et de confessions publié par le fils de la religieuse en 1654. Dans l'ensemble de ces écrits intimes, l'imaginaire du corps donne lieu à une véritable réflexion sur la différence. Que ce soit dans les paragraphes consacrés aux supplices réservés aux missionnaires jésuites par les Amérindiens, ou encore dans les nombreuses descriptions de la "saleté» des «Sauvages», tels que vus par l'épistolière, Marie de l'Incarnation accorde à l'altérité du continent découvert une corporalité problématique que seul le don mystique peut endiguer.

Dans un second texte, Pierre L'Hérault se penche sur l'insularité de Montréal et suggère une relecture fort intéressante de La nuit de Jacques Ferron. L'Hérault examine l'image paradoxale de l'île de Montréal, à la fois centralité et excentricité. Dans La nuit, la métropole est d'abord un lieu amérindien, puis ensuite, au moment

4 Alessandra Ferraro (dir.), Altérité et insularité. Relations croisées dans les cultures francophones/Alterità et insularità. Relazioni incrociate nelle culture francophone, Udine (Italie), Forum, 2005, 135 p. 
de l'implantation européenne, elle devient un avant-poste fluvial entre le lac SaintPierre et le lac Saint-Louis. Cette double référence structure l'imaginaire de Montréal chez Ferron, comme si l'île était faite de deux couches culturelles superposées: "C'est en entrant dans l'altérité radicale de l'île que le personnage découvre sa propre altérité, sa propre singularité.» (110) Pour L'Hérault, le roman interroge «la linéarité du rêve québécois» et envisage une nouvelle insularité métisse.

Enfin, Élisabeth Nardout-Lafarge propose une étude de l'imaginaire de l'île dans les romans de Réjean Ducharme. Chez cet écrivain, l'insularité est liée à l'innocence de l'enfance dans sa région natale de Saint-Ignace-de-Loyola, près de Berthier. Si l'île est "attachée aux pôles les plus valorisés de l'œuvre» (115), c'est qu'elle constitue un territoire miniaturisé aux dimensions du moi.

Dans sa préface, Ferraro explique qu'il est possible de concevoir l'altérité comme le signal d'une conception "polyphonique» des rapports interculturels. Loin d'être irréductible, l'autre évoluerait sur le mode de l'échange et de la négociation. Cette analyse, empreinte d'un fort optimisme quant à l'avenir des sociétés multiculturelles, ne tient pas suffisamment compte, à mon avis, de la fragilité stratégique des cultures insulaires et des marginalités culturelles. Souvent affaiblies par une émigration massive et confrontées à l'érosion de leurs institutions, les îles se nourrissent des tensions considérables qui les habitent. Nonobstant la qualité des études proposées, l'ouvrage issu du colloque d'Udine se contente donc de reprendre des conceptions assez conventionnelles du rapport à l'autre.

Enfin, il convient de dire un mot sur le livre de Svante Lindberg sur les représentations de l'altérité dans le roman québécois contemporains ${ }^{5}$. Cette thèse d'un jeune chercheur suédois s'inscrit dans la continuité des recherches de Jaap Lintvelt et de Józef Kwaterko sur ces mêmes questions. Lindberg conçoit l'altérité dans ses dimensions dialogiques, s'inspirant en cela des théories d'Émile Benveniste et de Simon Harel. S'il est vrai que la littérature québécoise est structurée par son histoire coloniale, il s'ensuit que le concept d'altérité doit être saisi comme le lieu allégorique d'une appropriation par un ensemble d'instances politiques dominantes. Dans son étude de certains romans des vingt dernières années, Lindberg n'hésite donc pas à extraire de chacun des récits «l'expression subjective pour aboutir à la signification d'ordre socioculturel» (59). La situation sociopolitique du Québec des années 1980 et les référendums de 1980 et de 1995 notamment lui semblent offrir un contexte essentiel à partir duquel les transformations identitaires, dont témoigne toujours l'espace romanesque analysé, peuvent être retracées.

L'intérêt de l'étude de Lindberg découle de l'originalité du corpus romanesque retenu. En effet, la lecture détaillée de six romans relativement peu commentés

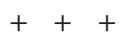

5 Svante Lindberg, Pratiques de l'ici, altérité et identité dans six romans québécois des années 1989-2002, Stockholm, Institutionen för franska, italienska och klassiska språk, 2005, 231 p. 
présente une perspective inédite sur une période contemporaine dont il nous est encore très difficile de saisir les tendances générales. Écho plus ou moins lointain du Survenant de Germaine Guèvremont, la figure de l'autre y est parfois celle de l'étranger dérangeant l'unanimité du lieu, comme dans La mort de Marlon Brando de Pierre Gobeil et L'hiver de pluie de Lise Tremblay, sujets du premier couple d'analyses proposées par Lindberg. À d'autres moments, l'altérité appartient au voyageur québécois en déplacement sur le territoire « centrifuge » de l'Amérique. Lindberg voit dans ce vaste territoire où se perdent les héros de Rober Racine et de Bertrand Gervais «une Amérique comme un palimpseste culturel où se mélangent des éléments dérivant du côté de la topographie, de l'anthropologique et du sacré» (113). Ailleurs et altérité se fusionnent et deviennent le lieu d'accueil d'une subjectivité en mouvement. Enfin, Lindberg consacre un dernier chapitre à l'expérience migratoire dans Un homme est une valse de Pauline Harvey et Visage retrouvé de Wajdi Mouawad. La lecture de ces deux œuvres convainc le critique que les notions d'altérité et de migrance ne peuvent être saisies en dehors de leur inscription dans l'espace collectif. En cela, par des chemins divers, Lindberg rejoint tout à fait Harel et Castillo Durante dans leur critique d'un pluralisme de bon aloi qui ne serait pas enraciné dans des espaces référentiels.

Certaines notions, disait Italo Calvino, « ont déjà une place assignée dans le contexte de l'information homogénéisée». Elles forment "un monde sur lequel pèse une épaisse croûte de discours ${ }^{6} »$. C'est assurément le cas aujourd'hui des concepts voisins d'altérité et de migrance que deux décennies de recherches subventionnées au Québec n'ont guère épargnés. Cela dit, ici comme ailleurs, l'identité résulte de pratiques fuyantes, difficiles à consigner de façon définitive. Je me dis maintenant, au moment d'envoyer cette chronique au secrétariat de Voix et Images, qu'il me faudra bien un jour récidiver, car les concepts comme les virus ne font que muter, ils ne se dissipent pas dans l'air du temps.

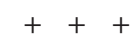

6 Italo Calvino, «Monde écrit et monde non écrit», Europe, no 815, 1997, p. 115. 